\title{
Resveratrol and curcumin enhance pancreatic $\beta$-cell function by inhibiting phosphodiesterase activity
}

Michael Rouse', Antoine Younès ${ }^{2}$ and Josephine M Egan'

${ }^{1}$ Laboratory of Clinical Investigation and 'Laboratory of Cardiovascular Science, National Institute on Aging, Intramural Research Program, National Institutes of Health, 251 Bayview Blvd, Baltimore, Maryland 21224, USA
Correspondence should be addressed to J M Egan

Email

eganj@grc.nia.nih.gov

\begin{abstract}
Resveratrol (RES) and curcumin (CUR) are polyphenols that are found in fruits and turmeric, and possess medicinal properties that are beneficial in various diseases, such as heart disease, cancer, and type 2 diabetes mellitus (T2DM). Results from recent studies have indicated that their therapeutic properties can be attributed to their anti-inflammatory effects. Owing to reports stating that they protect against $\beta$-cell dysfunction, we studied their mechanism(s) of action in $\beta$-cells. In T2DM, cAMP plays a critical role in glucose- and incretin-stimulated insulin secretion as well as overall pancreatic $\beta$-cell health. A potential therapeutic target in the management of T2DM lies in regulating the activity of phosphodiesterases (PDEs), which degrade CAMP. Both RES and CUR have been reported to act as PDE inhibitors in various cell types, but it remains unknown if they do so in pancreatic $\beta$-cells. In our current study, we found that both RES $(0.1-10 \mu \mathrm{mol} / \mathrm{l})$ and CUR (1-100 pmol/l)-regulated insulin secretion under glucose-stimulated conditions. Additionally, treating $\beta$-cell lines and human islets with these polyphenols led to increased intracellular CAMP levels in a manner similar to 3-isobutyl-1-methylxanthine, a classic PDE inhibitor. When we investigated the effects of RES and CUR on PDEs, we found that treatment significantly downregulated the mRNA expression of most of the 11 PDE isozymes, including PDE3B, PDE8A, and PDE10A, which have been linked previously to regulation of insulin secretion in islets. Furthermore, RES and CUR inhibited PDE activity in a dose-dependent manner in $\beta$-cell lines and human islets. Collectively, we demonstrate a novel role for natural-occurring polyphenols as PDE inhibitors that enhance pancreatic $\beta$-cell function.
\end{abstract}

\section{Key Words}

- type 2 diabetes

- resveratrol

- curcumin

- phosphodiesterase

- $\beta$-cell

\section{Introduction}

Diabetes mellitus (DM) is a chronic metabolic disease that, in 2013, by global estimates has a worldwide prevalence of 382 million people. The number is expected to increase to 592 million by 2035, most having type 2 DM (T2DM; Guariguata et al. 2014). T2DM is generally associated with abdominal obesity and dyslipidemia, which can be brought about by calorie-dense diets and sedentary lifestyles (Mokdad et al. 2003, Samson \& Garber 2014). Pancreatic $\beta$-cells are key players in the development of $\mathrm{T} 2 \mathrm{DM}$, as they are required to secrete increasing amounts 
of insulin so as to compensate for increasing insulin resistance. Consequently, the $\beta$-cells come under increasing metabolic stress and finally their function deteriorates (Marshak et al. 1999, Kahn 2003). Thus, it is important to find a means to preserve the health of $\beta$-cells.

Cyclic nucleotide phosphodiesterases (PDEs) belong to a class of enzymes that hydrolyze the phosphodiester bonds of cAMP and cGMP, thereby modulating various cellular signaling pathways. Thus far, eleven families of PDEs have been uncovered, which vary in their affinities for cAMP and cGMP as well as in expression levels within tissues (Cote et al. 2007). In fact, multiple PDEs along with their associated isozymes have been reported to be expressed at both mRNA and protein levels in rodent islets and $\beta$-cell lines (Härndahl et al. 2002, Cantin et al. 2007, Dov et al. 2008, Waddleton et al. 2008). Family-selective PDE inhibitors have proven to be very valuable tools for determining specific functions of selected PDEs and their roles in the developments in certain diseases. Several studies, for example, have demonstrated that inhibition of PDE3B (Härndahl et al. 2002, Waddleton et al. 2008), PDE8B (Dov et al. 2008), and PDE10A (Cantin et al. 2007) expression enhances $\beta$-cell function by promoting insulin secretion in response to glucose in rat $\beta$-cells.

Resveratrol (RES; 3,4',5-trihydroxystilbene) is a polyphenolic compound found in grapes, berries, and peanuts. Reports of recent studies have described a number of health benefits that can be attributed to RES, such as its ability to serve as a chemopreventive agent by augmenting cAMP in human breast cancer cells (El-Mowafy \& Alkhalaf 2003) and offering protection in cardiovascular disease through increased cGMP production in coronary arterial smooth muscle cells (El-Mowafy 2002). Furthermore, RES has been shown to possess therapeutic potential in the fight against obesity and T2DM (Beaudeux et al. 2010). In one study, RES was found to improve the health and survival of mice fed on a high-calorie diet (Baur et al. 2006). Results from another study indicated that RES treatment protected mice against diet-induced obesity and insulin resistance (Lagouge et al. 2006). The extent of beneficial effects of RES has also been tested in a number of diabetic models including streptozotocin (STZ), nicotinamide/STZ, and long-term high-fat diets (Su et al. 2006, Szkudelski \& Szkudelska 2011, Fiori et al. 2013). Recent studies in humans have revealed that RES supplementation improved glycemic control, and insulin sensitivity, and reduced oxidative stress in T2DM patients (Kar et al. 2009, Brasnyó et al. 2011, Bhatt et al. 2012).

For centuries, turmeric has been used in traditional medicine to treat various ailments and diseases.
Additionally, curcumin (CUR) supplementation has been noted as having many health benefits (Aggarwal et al. 2003). CUR, like RES, is a natural polyphenol that has shown great potential as a novel therapeutic agent due to its pharmacological safety and efficacy in treating a wide variety of human diseases. As an anti-oxidant, CUR has been shown to reverse STZ-induced hyperglycemia/glucose tolerance, hypoinsulinemia, and damage of pancreatic islets (El-Azab et al. 2011). CUR was also able to protect human islets from oxidative stress by increasing the mRNA and protein expression of heme oxygenase 1, glutathione, and $\mathrm{NAD}(\mathrm{P}) \mathrm{H}$ :quinone oxidoreductase 1 (Balamurugan et al. 2009). Results have also indicated that CUR treatment has anti-inflammatory properties in patients with inflammatory bowel diseases (Holt et al. 2005). More recently, CUR has emerged as a potential means to prevent and treat diabetes. This assertion comes after a 9-month study, involving a pre-diabetic population, which demonstrated that CUR treatment could not only lower HbA1c and homeostasis model assessment of insulin resistance (HOMA-IR) levels (a measure of insulin sensitivity), but also decelerate the deterioration of pre-diabetes to T2DM (Chuengsamarn et al. 2012). In addition, other studies have revealed CUR's ability to ameliorate hyperglycemic and hyperlipidemic conditions in diabetic animals (Arun \& Nalini 2002, Hussain 2002, Pari \& Murugan 2005). However, despite the wealth of health benefits provided by RES and CUR, particularly in the realm of diabetes, the molecular targets and mechanisms of action remain abstruse.

In the current study, we investigate the effects of RES and CUR on pancreatic $\beta$-cell function. We found that under both low- and high-glucose conditions, treatment with either RES or CUR led to a significant increase in insulin secretion in mouse $\beta$-Min6 cells as well as human islets. Treatment with these natural products also augmented intracellular levels of cAMP, an important second messenger in the insulin secretion pathway. We then developed a novel PDE activity assay so that we could directly assay PDE activity in $\beta$-cells. Our results indicate that RES and CUR enhance $\beta$-cell function by regulating PDE expression and activity, thus increasing intracellular cAMP levels and subsequent insulin secretion.

\section{Materials and methods}

\section{Reagents}

RES was purchased from Tocris Bioscience (Minneapolis, MN, USA). CUR, 3-isobutyl-1-methylxanthine (IBMX), DMSO, D-glucose, ATP assay mix, calmodulin from bovine

Published by Bioscientifica Ltd 
heart, myokinase (adenylate kinase) from rabbit muscle, pyruvate kinase from rabbit muscle, cAMP, ATP, AMP, CTP, PEP, dithiothreitol (DTT), Protease Inhibitor Cocktail, and all other chemicals used in this study were obtained from Sigma.

\section{Cell culture}

$\beta$-Min6 cells were maintained at $37^{\circ} \mathrm{C}$ in an atmosphere of $5 \% \mathrm{CO}_{2}$ in high glucose DMEM, which was supplemented with $15 \%$ heat-inactivated fetal bovine serum, $1 \%$ penicillin/streptomycin, and sodium pyruvate. Human pancreatic islet $\beta$-cells HP62, an epithelial human pancreatic islet cell line of insular origin generated by transfection of islet monolayer cultures with the plasmid pX8, which contains SV40 early region, were provided by Drs Marta Vives and Ricardo Pujol-Borrell. HP62 cells retain insulin production during the initial six passages and were maintained at $37{ }^{\circ} \mathrm{C}$ in an atmosphere of $5 \% \mathrm{CO}_{2}$ in RPMI 1640 medium, which was supplemented with $10 \%$ heat-inactivated fetal bovine serum, $1 \%$ penicillin/ streptomycin, $2 \mathrm{mmol} / \mathrm{l}$ glutamine, $0.5 \%$ transferrin, and $10 \mathrm{nmol} / 1$ hydrocortisone (Soldevila et al. 1991). Human islets were maintained at $37^{\circ} \mathrm{C}$ in an atmosphere of $5 \%$ $\mathrm{CO}_{2}$ in CMRL medium consisting of $5.5 \mathrm{mmol} / \mathrm{l}$ glucose, $1 \%$ penicillin/streptomycin, $2 \mathrm{mmol} / \mathrm{l}$ glutamine, and 3\% BSA. Stock Krebs buffer ( $\mathrm{pH}$ 7.4) was saturated with $95 \%$ $\mathrm{O}_{2} / 5 \% \mathrm{CO}_{2}$, and contained $137 \mathrm{mmol} / \mathrm{l} \mathrm{NaCl}, 4.7 \mathrm{mmol} / \mathrm{l}$ $\mathrm{KCl}, 1.2 \mathrm{mmol} / \mathrm{l} \mathrm{KHPO}_{4}, 1.2 \mathrm{mmol} / \mathrm{l} \mathrm{MgSO}_{4}-7 \mathrm{H}_{2} \mathrm{O}$, $2.5 \mathrm{mmol} / \mathrm{l} \mathrm{CaCl}_{2}-2 \mathrm{H}_{2} \mathrm{O}$, and $25 \mathrm{mmol} / 1 \mathrm{NaHCO}_{3}$.

\section{Insulin secretion assay}

$\beta$-Min6 cells (passages 9-12) were seeded at a density of $4 \times 10^{6}$ cells/well in a 12 -well plate for $24 \mathrm{~h}$ at $37^{\circ} \mathrm{C}$ in an atmosphere of $5 \% \mathrm{CO}_{2}$. Human islets were separated into $60 \mathrm{~cm}$ dishes containing 50 islets/dish. Cells were washed three times with glucose-free Krebs buffer, and then incubated in $0.05 \%$ BSA Krebs buffer $(1 \mathrm{mmol} / 1$ glucose) for $1 \mathrm{~h}$ at $37^{\circ} \mathrm{C}$ in an atmosphere of $5 \% \mathrm{CO}_{2}$. Cells were again washed three times with glucose-free Krebs buffer. Afterwards, cells were cultured in $0.05 \%$ BSA Krebs buffer ( 1 or $25 \mathrm{mmol} / \mathrm{l}$ glucose) and treated with vehicle, IBMX, RES, or CUR at the indicated doses for $2 \mathrm{~h}$. Supernatants were collected for insulin measurements using the Ultra-Sensitive Mouse Insulin ELISA Kit (Crystal Chemical, Inc., Downers Grove, IL, USA) for mouse or the Mercodia Insulin ELISA Kit (Mercodia, Winston Salem, NC, USA) for human cells, and performed according to the manufacturer's instructions.

\section{Intracellular cAMP assay}

$\beta$-Min6 cells (passages 9-12) were seeded at a density of $4 \times 10^{6}$ cells/well in a 12 -well plate for $24 \mathrm{~h}$ at $37^{\circ} \mathrm{C}$ in an atmosphere of $5 \% \mathrm{CO}_{2}$. Mouse insulinoma cells were washed three times with glucose-free Krebs buffer before being placed in $0.05 \%$ BSA Krebs buffer ( $1 \mathrm{mmol} / \mathrm{l}$ glucose) for $1 \mathrm{~h}$ at $37^{\circ} \mathrm{C}$ in an atmosphere of $5 \% \mathrm{CO}_{2}$. After washing again with glucose-free Krebs buffer, cells were cultured in $0.05 \%$ BSA Krebs buffer ( $1 \mathrm{mmol} / 1$ glucose $)$ and treated with vehicle, IBMX, RES, or CUR at the indicated doses. Primary human islets were plated at a concentration of 50 islets $/ 60 \mathrm{~mm}$ dish in CMRL media (5 or $25 \mathrm{mmol} / \mathrm{l}$ glucose) containing 3\% BSA and treated with RES or CUR at the indicated doses. Media were then removed and cells lysed using $0.1 \mathrm{~mol} / \mathrm{l} \mathrm{HCl}$. Lysates were spun down to remove debris, while lysate supernatants were collected for intracellular cAMP measurements using a Direct cAMP ELISA Kit according to the manufacturer's instructions (ENZO Life Sciences, Farmingdale, NY, USA).

\section{Quantitative PCR}

RNA was extracted using TRIzol (Invitrogen) and an RNeasy Mini Kit (Qiagen). RNA from mouse $\beta$-Min6 (passages 9-12) and human HP62 cell lines (passages 4-6) was converted into cDNA using qScript cDNA Supermix (Quanta Biosciences, Gaithersburg, MD, USA). RNA from human islets was converted into cDNA using a SuperScript III First-Strand Synthesis System (Invitrogen). PDE expression in $\beta$-Min6 and human HP62 cell lines as well as human islets was quantified using SYBR Green (Quanta Biosciences), and values were normalized to $18 \mathrm{~S}$ (Ambion, Austin, TX, USA). Quantitative PCR was performed on an ABI Prism 7300 (Applied Biosystems) detection system. The mouse primers were: Pde $3 b$ (forward: 5'-AGTATCAGTAGCTTGATGGGTGC-3' and reverse: 5'-CCCTTGTGAAGTTTTCGATCTCC-3'), Pde8a (forward: 5'-TGCAATTTGGCCCGATGAGAT- $3^{\prime}$ and reverse: 5'-TGGAATCCGTTACACTGGCTA-3'), and Pde10a (forward: 5'-AGGATACGAATATGCAGGGAGT-3' and reverse: 5'-CCGTCGGCTTTTGTGGCTAT-3') (Integrated DNA Technologies, Coralville, IA, USA). The human primers were: PDE3B (forward: 5'-TTCAGGAGACCGTCGTTGC-3' and reverse: 5'-TGACACCATATTGCGAGCCTC-3'), PDE8A (forward: 5'-AAAACCCCAACATCATGGCCT- $3^{\prime}$ and reverse: $5^{\prime}$-CCTGAGTTTCAGTTGTGATCGC-3'), and PDE10A (forward: 5'-GAGACAACCAGCTACTCCTCT- $3^{\prime}$ and reverse: 5'-ACAGGCTATTATTGCACTCTCCA-3') (Integrated DNA Technologies).

Published by Bioscientifica Ltd

Downloaded from Bioscientifica.com at $04 / 26 / 2023$ 12:53:41PM via free access 


\section{PDE activity assay}

Mouse $\beta$-Min6 (passages 9-12) or human HP62 cells (passages 4-6) were seeded into $100 \mathrm{~cm}$ dishes at $37^{\circ} \mathrm{C}$ in an atmosphere of $5 \% \mathrm{CO}_{2}$ until $80 \%$ confluency was reached in a fresh culture medium. Human islets were provided by the National Institute of Diabetes and Digestive and Kidney Diseases-funded Integrated Islet Distribution Program at the City of Hope. For primary cultures, human islets were placed in $100 \mathrm{~cm}$ dishes containing 150 islets/dish. Cells were washed three times with glucose-free Krebs buffer and then incubated in $0.05 \%$ BSA Krebs buffer ( $1 \mathrm{mmol} / 1$ glucose) for $1 \mathrm{~h}$ at $37^{\circ} \mathrm{C}$ in an atmosphere of $5 \% \mathrm{CO}_{2}$. Cells were again washed three times with glucose-free Krebs buffer. Afterwards, $\beta$-Min6 and HP62 cells were cultured in 0.05\% BSA Krebs buffer ( 1 or $25 \mathrm{mmol} / 1$ glucose) for $2 \mathrm{~h}$, while primary human islets were cultured in $0.05 \%$ BSA Krebs buffer ( 5 or $25 \mathrm{mmol} / \mathrm{l}$ glucose) for $2 \mathrm{~h}$. Then, cells were homogenized in cell lysis buffer containing $20 \mathrm{mmol} / 1$ HEPES (pH 7.4), $0.5 \mathrm{mmol} / \mathrm{l}$ EDTA, $2 \mathrm{mmol} / 1 \mathrm{MgCl}_{2}, 0.1 \%$ Triton $\mathrm{X}-100,0.5 \mathrm{mmol} / \mathrm{l} \mathrm{DTT}, 1 \mathrm{mmol} / \mathrm{l}$ EGTA, and Protease Inhibitor Cocktail. Lysates were filtered on GE Healthcare (Pittsburgh, PA, USA) PD MidiTrap G-25 sample preparation columns (Fisher Scientific, Pittsburgh, PA, USA), and the protein concentration was determined by BCA Protein Assay (Pierce, Rockford, IL, USA). Assay buffers were spiked with vehicle, RES, or CUR as indicated before being added to cell lysates. Bioluminescence PDE activity assays were performed in 96-well plates (Opaque Proxiplate half-area microplates, Perkin Elmer, Waltham, MA, USA) using a Promega GloMax Multi-Detection System as described previously (Younès et al. 2011).

\section{Statistical analysis}

Quantitative data are expressed as the mean \pm s.e.m. Differences between mean values were compared statistically by one-way ANOVA followed by the Bonferroni's post hoc comparison. A $P$ value of $<0.05$ was considered statistically significant.

\section{Results}

\section{RES and CUR enhance pancreatic $\beta$-cell function}

We treated $\beta$-Min 6 cells with different doses of RES and CUR for $2 \mathrm{~h}$. These doses have been reported to be biologically achievable based on bioavailability and pharmacokinetic studies in animals and humans (Shoba et al. 1998, Lao et al. 2006, Yoshino et al. 2012, Poulsen et al. 2013).
In addition, cells were cultured under low- $(1 \mathrm{mmol} / \mathrm{l})$ and high- $(25 \mathrm{mmol} / \mathrm{l})$ glucose conditions. We found that RES $(0.1-1 \mu \mathrm{mol} / \mathrm{l})$ increased insulin secretion in a dosedependent manner under low-glucose conditions (Fig. 1A). When cultured under high-glucose conditions, we observed that all three doses of RES $(0.1-10 \mu \mathrm{mol} / \mathrm{l})$ significantly increased insulin secretion compared with control. Similarly, CUR, albeit at significantly lower doses (1-10 pmol/l), markedly increases insulin secretion under low-glucose conditions (Fig. 1B). In addition, CUR (up to $100 \mathrm{pmol} / \mathrm{l}$ ) greatly enhanced insulin secretion under highglucose conditions compared with secretion from untreated cells. We then investigated whether these polyphenols could elicit similar effects in human islets. When examining the effects of the polyphenols on human islets, we found that slightly higher concentrations of RES $(1-10 \mu \mathrm{mol} / \mathrm{l})$ were required to significantly enhance insulin secretion compared with non-treated islets when cultured under low- $(5 \mathrm{mmol} / \mathrm{l})$ or high- $(25 \mathrm{mmol} / \mathrm{l})$ glucose conditions (Fig. 1C). CUR, on the other hand, was able to significantly augment insulin secretion compared with non-treated islets at a dose of 1-100 pmol/1 (Fig. 1D). Treatment with either RES or CUR was found to maintain heightened insulin levels at $24 \mathrm{~h}$; however, the combination RES+ CUR either did not yield any additional benefits or reduced the beneficial effects observed with the individual treatments (Supplementary Figs 1 and 2, see section on
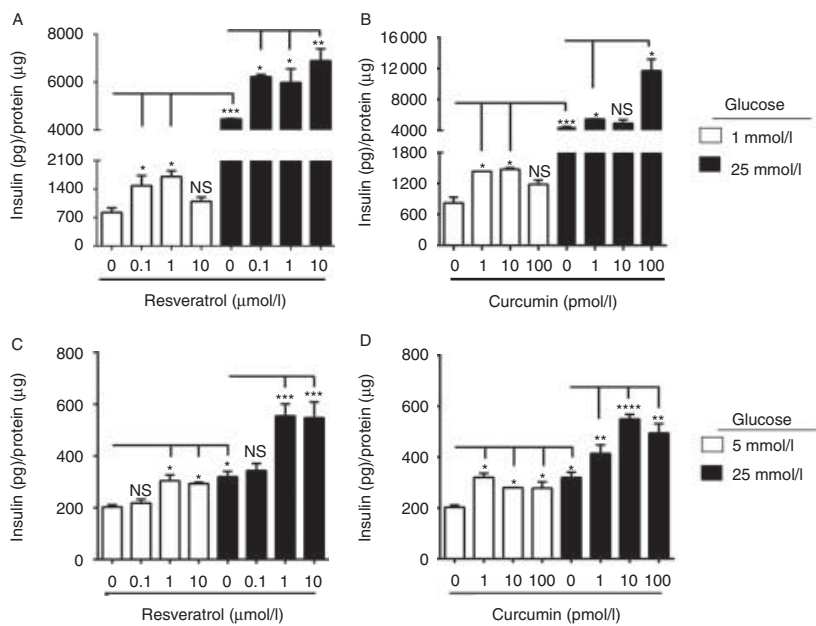

Figure 1

Resveratrol (RES) and curcumin (CUR) enhance insulin secretion in pancreatic $\beta$-cells. Mouse $\beta$-Min6 cells were treated with (A) RES or (B) CUR for $2 \mathrm{~h}$ under low- $(1 \mathrm{mmol} / \mathrm{l})$ or high- $(25 \mathrm{mmol} / \mathrm{l})$ glucose conditions. Primary human islets ( $n=2$ donors) were incubated with (C) RES or (D) CUR for $2 \mathrm{~h}$ under low- $(5 \mathrm{mmol} / \mathrm{l})$ or high- $(25 \mathrm{mmol} / \mathrm{l})$ glucose conditions. Supernatants from triplicate samples were analyzed for insulin secretion $(* P<0.05, * * P<0.01, * * * P<0.001$, and $* * * * P<0.0001)$. Data are representative of at least three independent experiments.

Published by Bioscientifica Ltd 

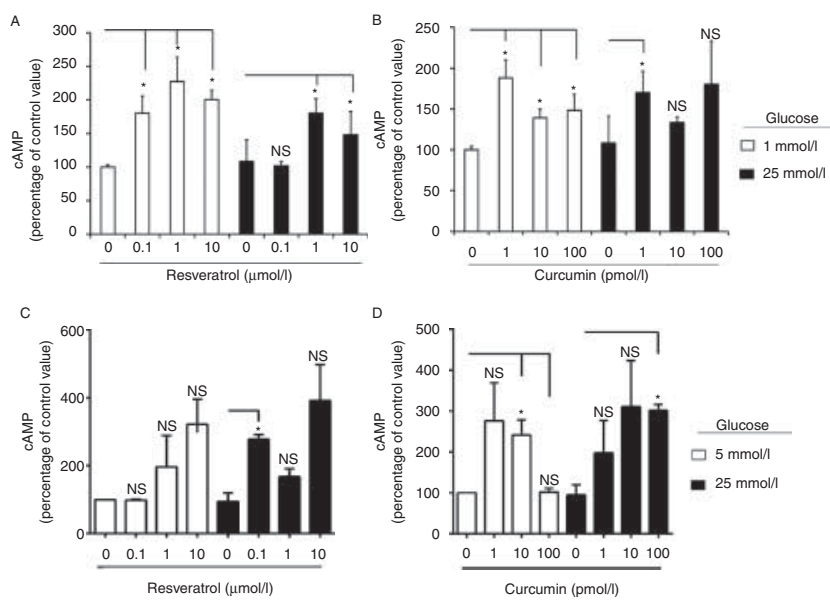

Figure 2

Resveratrol (RES) and curcumin (CUR) increase intracellular cAMP levels in $\beta$-cells. Mouse $\beta$-Min6 cells were treated with (A) RES or (B) CUR for $2 \mathrm{~h}$ under low- $(1 \mathrm{mmol} / \mathrm{l})$ or high- $(25 \mathrm{mmol} / \mathrm{l})$ glucose conditions. Primary human islets were treated with (C) RES or (D) CUR for $2 \mathrm{~h}$ under low( $5 \mathrm{mmol} / \mathrm{l})$ or high- $(25 \mathrm{mmol} / \mathrm{l})$ glucose conditions ( $n=2$ donors). Cells were lysed and assessed for intracellular cAMP levels after normalizing to protein content in triplicates $\left({ }^{\star} P<0.05\right)$. Data are representative of at least three independent experiments.

supplementary data at the end of this article). These results indicate that individual treatment with natural polyphenols, such as RES and CUR, can positively influence rodent as well as human $\beta$-cell function.

We then investigated the effects of RES and CUR on intracellular $\beta$-cell events. After $2 \mathrm{~h}$ of culture under lowglucose conditions, RES almost doubled intracellular cAMP levels in $\beta$-Min6 cells compared with untreated cells (Fig. 2A) and when cells were cultured under highglucose conditions, RES ( 1 and $10 \mu \mathrm{mol} / \mathrm{l}$ ) markedly increased intracellular cAMP levels. CUR also substantially increased intracellular cAMP levels in $\beta$-Min 6 cells under both low- and high-glucose conditions (Fig. 2B). When human islets were treated with RES or CUR, both polyphenols were able to increase intracellular levels (Fig. 2C and D). Again, the combination RES + CUR did not display an additive effect (Supplementary Fig. 3, see section on supplementary data given at the end of this article). These results indicate that RES and CUR probably enhance $\beta$-cell function under normal as well as diabetic conditions because of intracellular cAMP production and a consequent enhancement of insulin secretion.

PDEs belong to a class of enzymes capable of breaking the phosphodiester bonds that comprise second messenger molecules such as cAMP. Consequently, PDEs are considered important regulators of signal transduction of cAMP-mediated pathways, such as insulin secretion. To prove that inhibitors of PDEs augment cAMP levels and affect insulin secretion in our cell system, we treated $\beta$-Min6 cells with IBMX, a non-specific PDE inhibitor. We witnessed a significant rise in insulin secretion under low- and high-glucose conditions following IBMX $(50 \mu \mathrm{mol} / \mathrm{l})$ treatment (Fig. 3A). Subsequently, we also observed a substantial increase in intracellular cAMP levels compared with non-IBMX-treated cells (Fig. 3B). These results indicate that the blockade of PDEs enhances $\beta$-cell function through cAMP modulation.

\section{RES and CUR reduce PDE gene expression in $\beta$-cells}

We investigated the effects of RES and CUR on PDE gene expression and function to determine whether these polyphenolic compounds modulated PDEs in $\beta$-cells. We first examined the mRNA expression of known mouse Pde isoforms and established that a majority of them were downregulated following RES or CUR treatment (results not shown). As a result, we continued to focus primarily on three main $P d e$ isoforms reported to act as critical regulators in the insulin secretion pathway: Pde3b, Pde8a, and Pde10a (Fig. 4A). Using the lowest effective dose, RES $(0.1 \mu \mathrm{mol} / \mathrm{l})$ significantly reduced the relative mRNA expression of $P d e 3 b$, $P d e 8 a$, and Pde10a in mouse $\beta$-Min6 cells cultured under low-glucose conditions. CUR (1 pmol/l) also decreased Pde $3 b$, $P d e 8 a$, and Pde10a mRNA expression under low-glucose conditions. When the $\beta$-Min6 cells were cultured in a highglucose environment, RES-treated cells had significantly lower expression levels of $P d e 3 b$ and $P d e 10 a$, but there were no significant changes in Pde8a. Meanwhile, treatment with CUR under high-glucose conditions led to substantial decreases in Pde $3 b$ and Pde8a mRNA expression. CUR, however, did not appear to alter the expression of Pde10a in $\beta$-Min6 cells cultured under high-glucose conditions, indicating subtle differences in effects between CUR and RES.
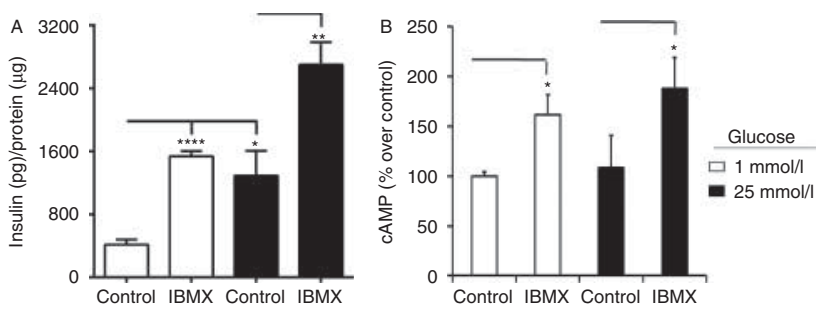

Figure 3

PDE blockade leads to enhanced insulin secretion and intracellular CAMP production. Mouse $\beta-M i n 6$ cells were treated with PDE inhibitor IBMX $(50 \mu \mathrm{mol} / \mathrm{l})$ for $2 \mathrm{~h}$ under low- $(1 \mathrm{mmol} / \mathrm{l})$ or high- $(25 \mathrm{mmol} / \mathrm{l})$ glucose conditions. Cells were examined for (A) insulin secretion and (B) intracellular cAMP levels (normalized to protein content; $* P<0.05$, $* * P<0.01$, and $* * * * P<0.0001$ ). Samples were run in triplicate, and data are representative of at least three independent experiments.

Published by Bioscientifica Ltd 

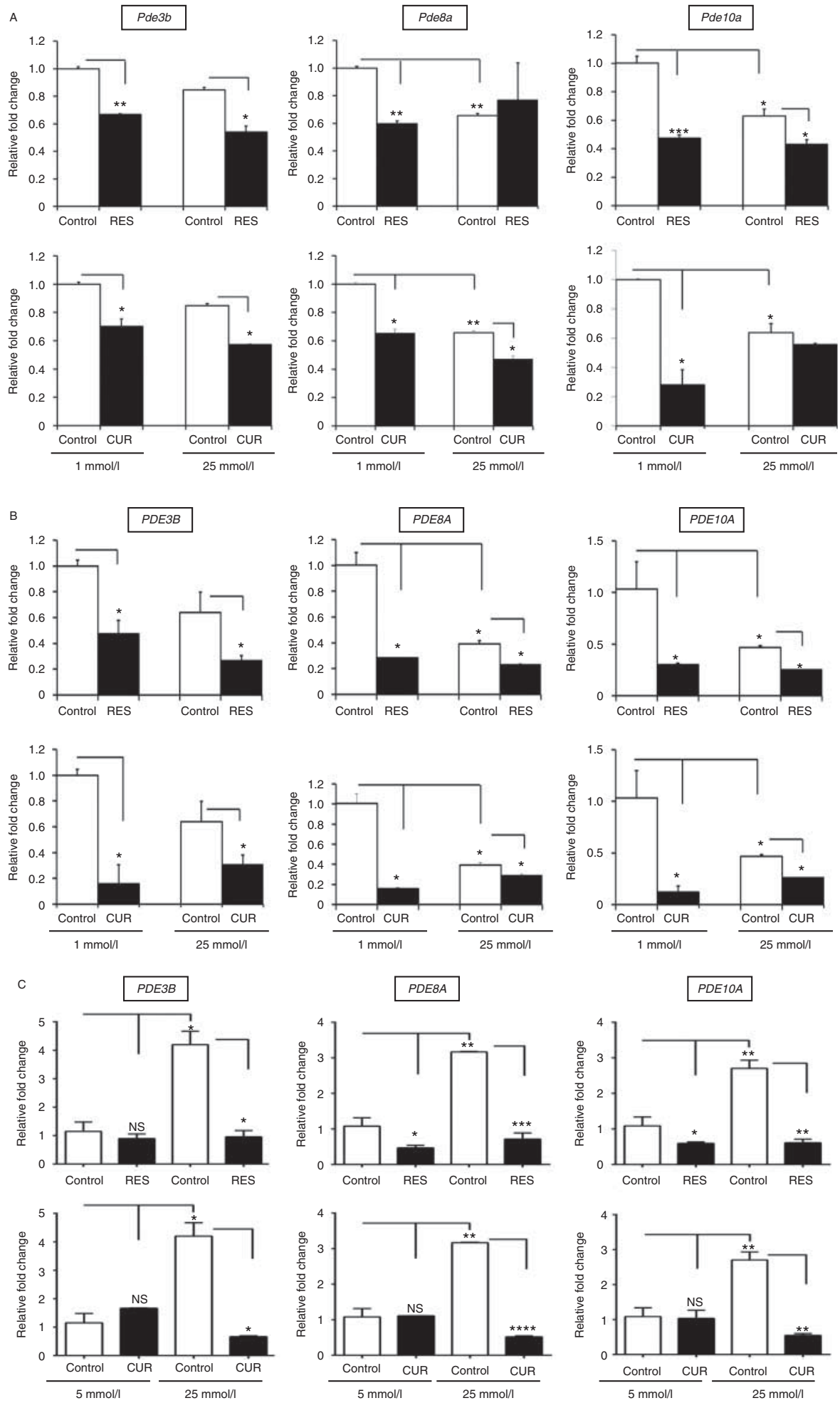

Figure 4

Resveratrol (RES) and curcumin (CUR) reduce PDE expression in $\beta$-cells. (A) Mouse $\beta$-Min 6 cells and (B) human HP62 $\beta$-cells were incubated with vehicle, RES $(0.1 \mu \mathrm{mol} / \mathrm{l})$, or CUR $(1 \mathrm{pmol} / \mathrm{l})$ for $2 \mathrm{~h}$ under low- $(1 \mathrm{mmol} / \mathrm{l})$ or high- $(25 \mathrm{mmol} / \mathrm{l})$ glucose conditions. (C) Primary human islets $(n=3$ donors) were incubated with vehicle, RES $(10 \mu \mathrm{mol} / \mathrm{l})$, or CUR $(100 \mathrm{pmol} / \mathrm{l})$

\begin{tabular}{|lr}
\hline http://joe.endocrinology-journals.org & ( 2014 The authors \\
DOI: $10.1530 / J O E-14-0335$ & Printed in Great Britain
\end{tabular}

for $2 \mathrm{~h}$ under low $(5 \mathrm{mmol} / \mathrm{l})$ or high $(25 \mathrm{mmol} / \mathrm{l})$ glucose conditions. Samples, ran in triplicate, were analyzed for relative $P D E$ mRNA expression using quantitative RT-PCR and results are expressed as mean + S.E.M. $(* P<0.05, * * P<0.01, * * * P<0.001, * * * * P<0.0001)$. Data are representative of at least three independent experiments. 
Following our studies using the mouse cell line, we investigated whether RES and CUR had similar effects on PDE mRNA expression in human HP62 $\beta$-cells. RES treatment $(0.1 \mu \mathrm{mol} / \mathrm{l})$ extensively reduced mRNA expression of three PDEs important in the insulin signaling pathway under low-glucose conditions, and it also displayed similar efficacy under high-glucose conditions (Fig. 4B). In HP62 $\beta$-cells, CUR treatment (1 pmol/l) also decreased the expression of PDE3B, PDE8A, and PDE1OA in both low and high glucose conditions. These results indicate that RES and CUR alter PDE expression independently from glucose in mouse as well as human $\beta$-cells.

To further investigate the translational applications of our study, we examined the effects of RES and CUR treatment on PDE mRNA expression in primary human islets (Fig. 4C). In these studies, RES treatment $(10 \mu \mathrm{mol} / \mathrm{l})$ was found to significantly diminish PDE8A and PDE1OA expression under low-glucose conditions, while dramatically reducing expression of all three PDEs under highglucose conditions. CUR (100 pmol/l), on the other hand, demonstrated no significant changes in the presence of low levels of glucose. However, CUR was able to substantially downregulate $P D E 3 B, P D E 8 A$, and $P D E 10 A$ in the presence of high levels of glucose. It is important to note that although higher doses of RES and CUR might be needed for treating human islets compared with insulinoma cell lines due to the heterogenous composition of islets, we observed similar therapeutic effects on PDE expression.

\section{RES and CUR impede PDE activity in pancreatic $\beta$-cells}

To directly study the ability of RES and CUR to act as PDE inhibitors in pancreatic $\beta$-cells, we developed an assay to directly measure the kinetics of PDE activity. In short, the PDE activity assay measures the degradation of cAMP to $5^{\prime}$-AMP by PDEs, thus levels of AMP increase at a directly proportional rate to the level of PDE activity within the system.

In the current study, cell lysates were collected from $\beta$-Min 6 cells cultured for $2 \mathrm{~h}$ under low- and highglucose conditions. Control lysates were passed through a G-25 sample preparation column and subjected to an enzymatic reaction to assess PDE activity. During the course of the study, lysates from cells cultured under high-glucose conditions displayed a slightly higher PDE activity compared with those cultured under lowglucose conditions (Fig. 5A). When various doses of RES (0.1-10 $\mu \mathrm{mol} / \mathrm{l})$ were added to low-glucose lysates, RES was found to reduce PDE activity in a dose-dependent manner. The effects of RES appeared to be even more marked in the high-glucose lysates, illustrating that
$10 \mu \mathrm{mol} / \mathrm{l}$ RES was most efficient at lowering PDE activity. When lysates of $\beta$-Min 6 cells were exposed to CUR, PDE activity was decreased to similar degrees with each dose of CUR (1-100 pmol/l) under both low- and high-glucose conditions.

Lysates from HP62 cells, under high-glucose conditions, had considerably elevated levels of PDE activity compared with lysates under low-glucose conditions (Fig. 5B). In lysates from cells cultured under low glucose conditions, RES lowered PDE activity in a dose-dependent manner. In lysates under high-glucose conditions, increasing concentration of RES also led to a decreased PDE activity. CUR under low-glucose conditions had little to no effect on PDE activity. Conversely, HP62 cells exposed to CUR (1-100 pmol/l) in the presence of high glucose levels exhibited marked reductions in PDE activity.

Finally, we measured PDE activity in human islets. In the process, we did observe a slightly modified profile of the PDE activity curve due to the heterogeneity of islets and multiple cell types expressing PDEs compared with the homogenous $\beta$-cell lines. However, islets exposed to high levels of glucose continue to exhibit increased PDE activity compared with those exposed to low levels of glucose (Fig. 5C). Although $0.1 \mu \mathrm{mol} / \mathrm{l}$ RES did not appear to alter PDE activity in lowglucose lysates, at $1-10 \mu \mathrm{mol} / 1$ it starkly inhibited PDE activity. In lysates under high-glucose conditions, increasing RES concentrations significantly reduced PDE activity. CUR $(1 \mathrm{pmol} / \mathrm{l})$ had minimal effect, whereas 10 and $100 \mathrm{pmol} / \mathrm{l}$ caused a notable decrease in PDE activity in lysates under low-glucose conditions, while under high-glucose conditions CUR at all concentrations tested was a powerful inhibitor of PDE activity. Collectively, these findings prove that RES and CUR directly impede PDE activity in pancreatic $\beta$-cells, and that this mechanism of action is conserved across species.

\section{Discussion}

In the current study, we explored the therapeutic prowess of natural products, specifically RES and CUR, in an attempt to enhance $\beta$-cell function. Previous animal models and human clinical trials have reported that oral administration of RES ( 5 mg-5 g; Carrizzo et al. 2013, Trimmers et al. 2013) or CUR (80 mg-6 g; Fan etal. 2013, Meng etal. 2013) given as a single dose or daily for up to 12 months to diabetics is able to reduce blood glucose and improve insulin sensitivity. Our results demonstrate the ability of RES and CUR to promote $\beta$-cell function across species by acting as direct PDE inhibitors in $\beta$-cells and islets. We found that treatment of mouse and human $\beta$-cells with RES and CUR resulted in a substantial reduction of PDE expression, particularly PDE3B,

Published by Bioscientifica Ltd 

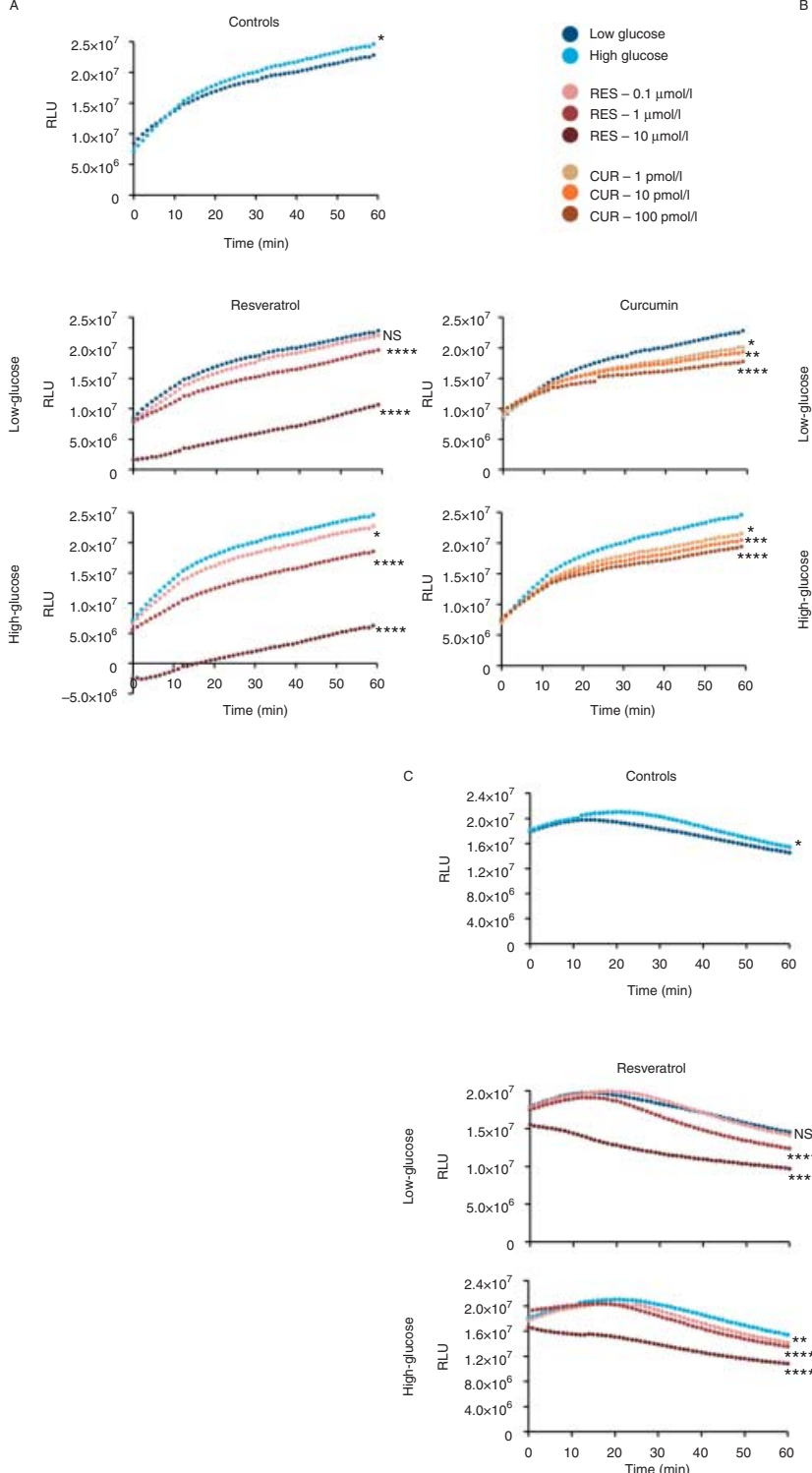
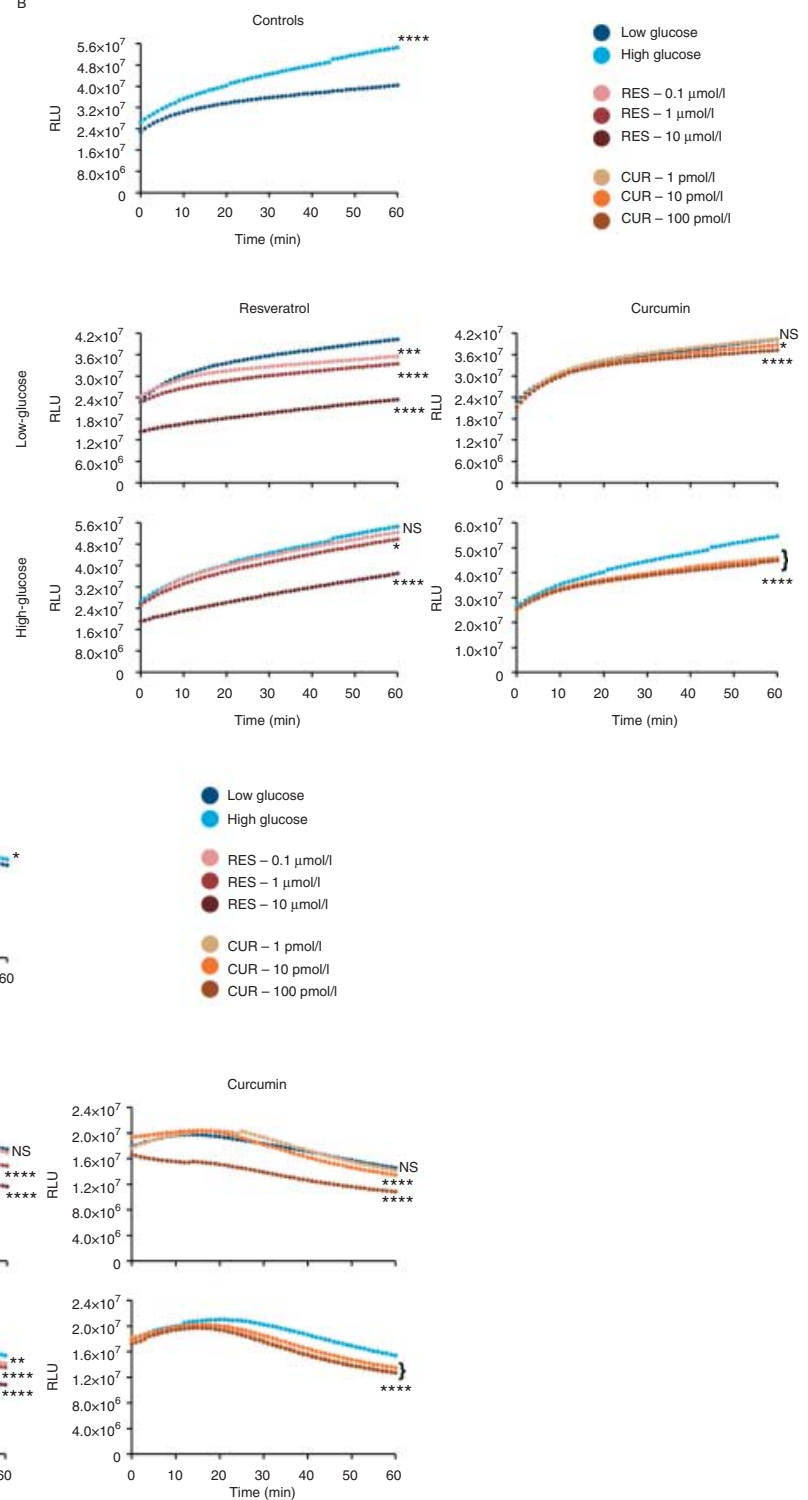

Figure 5

Resveratrol (RES) and curcumin (CUR) impede PDE activity in pancreatic $\beta$-cells. (A) Mouse $\beta$-Min6 cells and (B) human HP62 $\beta$-cells were cultured for $2 \mathrm{~h}$ under low- $(1 \mathrm{mmol} / \mathrm{l})$ or high- $(25 \mathrm{mmol} / \mathrm{l})$ glucose conditions.

(C) Primary human islets ( $n=2$ donors) were cultured for $2 \mathrm{~h}$ under low$(5 \mathrm{mmol} / \mathrm{l})$ or high- $(25 \mathrm{mmol} / \mathrm{l})$ glucose conditions. Cell lysates were treated

PDE8A, and PDE10A, which are known to be important in insulin signaling. Furthermore, RES and CUR treatment demonstrated a profound ability to directly inhibit PDE activity in $\beta$-cells as well as islets. As a result of PDE inhibition, RES and CUR treatment prevented the degradation of cAMP, thus leading to an increase in its intracellular levels. Subsequently, this allowed for activation of cAMP-dependent signaling pathways, thereby augmenting insulin secretion and $\beta$-cell function. with vehicle, RES, or CUR and analyzed for relative PDE activity using a bioluminescence reaction assay. Samples were run in triplicates and the mean was plotted $(* P<0.05, * * P<0.01, * * * P<0.001$, and $* * * * P<0.0001)$. Data are representative of at least three independent experiments.

Results from several studies have indicated that naturally occurring polyphenols RES and CUR have shown promise in the realm of diabetes. Previously, results from our laboratory indicated that long-term RES supplementation prevented decreased expression of the essential $\beta$-cell transcription factors forkhead box protein O1 (FOXO1), NKX6-1, NKX2-2, and $P D X 1$ in rhesus monkeys given a high-fat high-sugar diet. In addition, we observed a similar type of protection upon RES treatment in human islets cultured under

Published by Bioscientifica Ltd 
high-glucose + palmitate conditions (Fiori et al. 2013). In STZ-induced diabetic rats, CUR has demonstrated protection by displaying anti-oxidant and hypoglycemic properties (Hussain 2002, Pari \& Murugan 2005), while RES also reduced the elevated levels of blood glucose as well as albumin, urea, and creatinine (Soufi et al. 2012). Other studies have demonstrated that mice given a high-fat diet display obesity, hyperglycemia, and insulin resistance, which were reversed upon treatment with either RES or CUR (Baur et al. 2006, Shao et al. 2012). RES treatment has also been shown to prevent age-related decreases in insulin sensitivity in primates, such as gray mouse lemur (Microcebus murinus; Marchal et al. 2012). Moreover, RES and CUR treatment have been shown to be effective in patients with T2DM by improving insulin sensitivity, and decreasing fasting blood glucose, HbA1c, triglyceride levels, and body weight (Brasnyó et al. 2011, Chuengsamarn et al. 2012, Kumar \& Joghee 2013, Movahed et al. 2013). In the current study, we demonstrated that RES and CUR are able to significantly promote insulin secretion in mouse $\beta$-cell lines as well as human islets. The ability to enhance $\beta$-cell function was found to occur under both low- and highglucose-stimulated conditions within a matter of hours.

The beneficial health benefits observed after RES and CUR supplementation have been attributed to their anti-inflammatory and anti-oxidant properties and even their ability to mimic caloric restriction. While many studies have explored the effects of RES and CUR on hyperglycemia as a whole, there remains limited evidence regarding their influence on $\beta$-cells. Therefore, we investigated and established the effects of RES and CUR treatment on the enhancement of $\beta$-cell function through an alternative and novel mechanism; they are direct PDE inhibitors. While the concept of RES and CUR acting as PDE inhibitors is a relatively new development, there is a growing amount of evidence that advocate the idea. One study, for example, revealed that RES dynamically increased cAMP levels in myotubes, thus triggering downstream effectors, such as PKA and AMPK. Additionally, the surge of cAMP was attributed to RES acting as a competitive and non-selective inhibitor of multiple PDEs (Park et al. 2012) and not as a result of activating adenylate cyclase (Gerhart-Hines et al. 2011). Similarly, CUR exhibited inhibitory properties on multiple PDE isozymes to elicit an anti-cancer and anti-proliferative effect in melanoma cells (Abusnina et al. 2011). These reports corroborate our findings and the newfound aptitude of RES and CUR as PDE inhibitors in various tissue types.

PDEs, which belong to a family of enzymes that degrade cAMP and cGMP (Soderling \& Beavo 2000), serve as novel drug targets for treating various diseases, such as heart failure, depression, asthma, inflammation, and erectile dysfunction (Mehats et al. 2002, Rotella 2002). With regards to diabetes and insulin resistance, several PDEs have been noted to play important roles in regulating glucose tolerance through the modulation of cAMP-dependent processes. Rolipram, a selective PDE4 inhibitor, activated AMPK in myotubes, thus improving glucose tolerance in obese mice (Park et al. 2012). Previous studies have revealed that not only does isozyme PDE3B reside within insulin granules, but also that it mediates the acute first phase and the second sustained phase of insulin secretion (Walz et al. 2007). Moreover, the effects of PDE3B on $\beta$-cell function were further strengthened when the overexpression of PDE3B in mice led to impaired glucose-stimulated insulin secretion, glucose tolerance, and enhanced sensitivity to high-fatdiet-induced insulin resistance (Härndahl et al. 2002, 2004, Walz et al. 2006, 2007). In addition, blockade of PDE3B (Walz et al. 2007), PDE8B (Dov et al. 2008), and PDE10A (Cantin et al. 2007) expression and/or activity in pancreatic islets led to a significant increase in insulin secretion. Furthermore, in a study investigating diet-induced obesity, researchers found that inhibition of PDE10A, either through genetic deletion or pharmacological blockade, substantially increased weight loss and insulin sensitivity, while reducing adiposity in mice fed on a Western-style diet (Nawrocki et al. 2014).

Based on our observations, we are the first, to our knowledge, to show that treatment with RES or CUR leads to significant inhibition of PDE expression and activity in $\beta$-cells, thereby reducing the degradation of intracellular cAMP. In addition, individual treatment with RES or CUR markedly enhances $\beta$-cell function by triggering robust insulin secretion under low- and high-glucose conditions, whereas the combination RES + CUR hindered their beneficial effects. These findings indicate that RES and CUR could be acting through similar signaling pathways and may compete with each other for common substrates, such as PDE isozymes. Given the acute response of $\beta$-cells to these polyphenols, it would also be of interest to study the longterm effects on $\beta$-cell function following chronic treatment with RES or CUR. Similarly, as results from previous studies have indicated, PDEs play an important role in the regulation and development of T2DM and serve as critical therapeutic targets. Thus, it would be very informative to examine $P D E$ expression levels as well as activity in vivo upon supplementation with RES or CUR. The strengths of our study are that multiple cell lines and isolated islets displayed similar improvements in function upon RES or CUR treatment, and, for the first time, to our knowledge, we show that we can directly measure, in real time, PDE activity in islets using our

Published by Bioscientifica Ltd 
newly developed assay. Overall, the use of RES and CUR continues to show great therapeutic potential for enhancing $\beta$-cell function and mitigating the development of T2DM.

\section{Supplementary data}

This is linked to the online version of the paper at http://dx.doi.org/10.1530/ JOE-14-0335.

\section{Declaration of interest}

The authors declare that there is no conflict of interest that could be perceived as prejudicing the impartiality of the research reported.

\section{Funding}

This work was supported by the Intramural Research Program of the National Institute on Aging.

\section{Author contribution statement}

M R designed, developed, and performed experiments, analyzed data, and wrote the manuscript. A $Y$ designed and developed PDE activity assays in $\beta$-cells. M R and J M E were responsible for procuring human islets from the Integrated Islet Distribution Program and for the treatment of human islets. J M E contributed to the design of experiments, interpretation of data, and writing of the manuscript. All authors edited and reviewed the manuscript. J M E is the guarantor of this work and, as such, had full access to all the data in the study and takes responsibility for the integrity of the data and the accuracy of the data analysis.

\section{References}

Abusnina A, Keravis T, Yougbaré I, Bronner C \& Lugnier C 2011 Antiproliferative effect of curcumin on melanoma cells is mediated by PDE1A inhibition that regulates the epigenetic integrator UHRF1. Molecular Nutrition \& Food Research 55 1677-1689. (doi:10.1002/mnfr.201100307)

Aggarwal BB, Kumar A \& Bharti AC 2003 Anticancer potential of curcumin: preclinical and clinical studies. Anticancer Research 23 363-398.

Arun N \& Nalini N 2002 Efficacy of turmeric on blood sugar and polyol pathway in diabetic albino rats. Plant Foods for Human Nutrition $\mathbf{5 7}$ 41-52. (doi:10.1023/A:1013106527829)

Balamurugan AN, Akhov L, Selvaraj G \& Pugazhenthi S 2009 Induction of antioxidant enzymes by curcumin and its analogues in human islets: implications in transplantation. Pancreas 159 85-93. (doi:10.1097/ MPA.0b013e318196c3e7)

Baur JA, Pearson KJ, Price NL, Jamieson HA, Lerin C, Kalra A, Prabhu VV, Allard JS, Lopez-Lluch G, Lewis K et al. 2006 Resveratrol improves health and survival of mice on a high-calorie diet. Nature $\mathbf{4 4 4} 337-342$. (doi:10.1038/nature05354)

Beaudeux JL, Nivet-Antoine V \& Giral P 2010 Resveratrol: a relevant pharmacological approach for the treatment of metabolic syndrome? Current Opinion in Clinical Nutrition and Metabolic Care 13 729-736. (doi:10.1097/MCO.0b013e32833ef291)

Bhatt JK, Thomas S \& Nanjan MJ 2012 Resveratrol supplementation improves glycemic control in type 2 diabetes mellitus. Nutrition Research 32 534-541. (doi:10.1016/j.nutres.2012.06.003)

Brasnyó P, Molnár GA, Mohás M, Markó L, Laczy B, Cseh J, Mikolás E, Szijártó IA, Mérei A, Halmai R et al. 2011 Resveratrol improves insulin sensitivity, reduces oxidative stress and activates the Akt pathway in type 2 diabetic patients. British Journal of Nutrition $106383-389$. (doi:10.1017/S0007114511000316)

Cantin LD, Magnuson S, Gunn D, Barucci N, Breuhaus M, Bullock WH, Burke J, Claus TH, Daly M, Decarr L et al. 2007 PDE-10A inhibitors as insulin secretagogues. Bioorganic \& Medicinal Chemistry Letters 17 2869-2873. (doi:10.1016/j.bmcl.2007.02.061)

Carrizzo A, Forte M, Damato A, Trimarco V, Salzano F, Bartolo M, Maciag A, Puca AA \& Vecchione C 2013 Antioxidant effects of resveratrol in cardiovascular, cerebral and metabolic diseases. Food and Chemical Toxicology 61 215-226. (doi:10.1016/j.fct.2013.07.021)

Chuengsamarn S, Rattanamongkolgul S, Luechapudiporn R, Phisalaphong C \& Jirawatnotai S 2012 Curcumin extract for prevention of type 2 diabetes. Diabetes Care 35 2121-2127. (doi:10.2337/dc12-0116)

Cote RH 2007 Photoreceptor phosphodiesterase (PDE6): A G-proteinactivated PDE regulating visual excitation in rod and cone photoreceptor cells. In Cyclic Nucleotide Phosphodiesterases in Health and Disease, 1st Edn, Ch 8, pp 165-194. Eds J Beavo, S Francis \& M Houslay. Boca Raton, FL: CRC Press.

Dov A, Abramovitch E, Warwar N \& Nesher R 2008 Diminished phosphodiesterase-8B potentiates biphasic insulin response to glucose. Endocrinology 149 741-748. (doi:10.1210/en.2007-0968)

El-Azab MF, Attia FM \& El-Mowafy AM 2011 Novel role of curcumin combined with bone marrow transplantation in reversing experimental diabetes: effects on pancreatic islet regeneration oxidative stress, and inflammatory cytokines. European Journal of Pharmacology 658 41-48. (doi:10.1016/j.ejphar.2011.02.010)

El-Mowafy AM 2002 Resveratrol activates membrane-bound guanylyl cyclase in coronary arterial smooth muscle: a novel signaling mechanism in support of coronary protection. Biochemical and Biophysical Research Communications 291 1218-1224. (doi:10.1006/bbrc.2002.6598)

El-Mowafy AM \& Alkhalaf M 2003 Resveratrol activates adenylyl-cyclase in human breast cancer cells: a novel, estrogen receptor-independent cytostatic mechanism. Carcinogenesis 24 869-873. (doi:10.1093/carcin/bgg015)

Fan X, Zhang C, Liu D, Yan J \& Liang H 2013 The clinical applications of curcumin: current state and the future. Current Pharmaceutical Design 19 2011-2031. (doi:10.2174/1381612811319110005)

Fiori JL, Shin YK, Kim W, Krzysik-Walker SM, González-Mariscal I, Carlson OD, Sanghvi M, Moaddel R, Farhang K, Gadkaree SK et al. 2013 Resveratrol prevents $\beta$-cell dedifferentiation in nonhuman primates given a high-fat/high-sugar diet. Diabetes 62 3500-3513. (doi:10.2337/db13-0266)

Gerhart-Hines Z, Dominy JE Jr, Blättler SM, Jedrychowski MP, Banks AS, Lim JH, Chim H, Gygi SP \& Puigserver P 2011 The cAMP/PKA pathway rapidly activates SIRT1 to promote fatty acid oxidation independently of changes in $\mathrm{NAD}^{+}$. Molecular Cell 44 851-863. (doi:10.1016/j.molcel. 2011.12.005)

Guariguata L, Whiting DR, Hambleton I, Beagley J, Linnenkamp U \& Shaw JE 2014 Global estimates of diabetes prevalence for 2013 and projections for 2035. Diabetes Research and Clinical Practice 103 137-149. (doi:10.1016/j.diabres.2013.11.002)

Härndahl L, Jing XJ, Ivarsson R, Degerman E, Ahrén B, Manganiello VC, Renström E \& Holst LS 2002 Important role of phosphodiesterase 3B for the stimulatory action of cAMP on pancreatic $\beta$-cell exocytosis and release of insulin. Journal of Biological Chemistry 277 37446-37455. (doi:10.1074/jbc.M205401200)

Härndahl L, Jing XJ, Ivarsson R, Degerman E, Ahrén B, Manganiello VC, Renström E \& Holst LS $2004 \beta$-Cell-targeted overexpression of phosphodiesterase $3 \mathrm{~B}$ in mice causes impaired insulin secretion, glucose intolerance, and deranged islet morphology. Journal of Biological Chemistry 279 15214-15222. (doi:10.1074/jbc.M308952200)

Holt PR, Katz S \& Kirshoff R 2005 Curcumin therapy in inflammatory bowel disease: a pilot study. Digestive Diseases and Sciences 50 2191-2193. (doi:10.1007/s10620-005-3032-8)

Hussain HE 2002 Hypoglycemic, hypolipidemic, and antioxidant properties of combination of curcumin from Curcuma longa, Linn, and partially purified product from Abroma augusta, Linn. in streptozotocin 
induced diabetes. Indian Journal of Clinical Biochemistry 17 33-43. (doi:10.1007/BF02867969)

Kahn SE 2003 The relative contribution of insulin resistance and $\beta$ cell dysfunction to the pathophysiology of type 2 diabetes. Diabetologia 46 3-19. (doi:10.1007/s00125-003-1190-9)

Kar P, Laight D, Rooprai HK, Shaw KM \& Cummings M 2009 Effects of grape seed extract in type 2 diabetic subjects at high cardiovascular risk: a double blind randomized placebo controlled trial examining metabolic markers, vascular tone, inflammation, oxidative stress and insulin sensitivity. Diabetic Medicine 26 526-531. (doi:10.1111/ j.1464-5491.2009.02727.x)

Kumar BJ \& Joghee NM 2013 Resveratrol supplementation in patients with type 2 diabetes mellitus: a prospective, open label, randomized controlled trial. International Research Journal of Pharmacy 4 245-249. (doi:10.7897/2230-8407.04849)

Lagouge M, Argmann C, Gerhart-Hines Z, Meziane H, Lerin C, Daussin F, Messadeq N, Milne J, Lambert P, Elliott P et al. 2006 Resveratrol improves mitochondrial function and protects against metabolic disease by activating SIRT1 and PGC-1 $\alpha$. Cell 127 1109-1122. (doi:10.1016/j.cell.2006.11.013)

Lao CD, Ruffin MT IV, Normolle D, Heath DD, Murray SI, Bailey JM, Boggs ME, Crowell J, Rock CL \& Brenner DE 2006 Dose escalation of a curcuminoid formulation. BMC Complementary and Alternative Medicine 6 10. (doi:10.1186/1472-6882-6-10)

Marchal J, Blanc S, Epelbaum J, Aujard F \& Pifferi F 2012 Effects of chronic calorie restriction or dietary resveratrol supplementation on insulin sensitivity markers in a primate, Microcebus murinus. PLOS ONE 7 e34289. (doi:10.1371/journal.pone.0034289)

Marshak S, Leibowitz G, Bertuzzi F, Socci C, Kaiser N, Gross DJ, Cerasi E \& Melloul D 1999 Impaired $\beta$-cell functions induced by chronic exposure of cultured human pancreatic islets to high glucose. Diabetes $\mathbf{4 8}$ 1230-1236. (doi:10.2337/diabetes.48.6.1230)

Mehats C, Andersen CB, Filopanti M, Jin SL \& Conti M 2002 Cyclic nucleotide phosphodiesterases and their role in endocrine cell signaling. Trends in Endocrinology and Metabolism 13 29-35. (doi:10.1016/S1043-2760(01)00523-9)

Meng B, Li J \& Cao H 2013 Antioxidant and antiinflammatory activities of curcumin on diabetes mellitus and its complications. Current Pharmaceutical Design 19 2101-2113. (doi:10.2174/1381612811319110011)

Mokdad AH, Ford ES, Bowman BA, Dietz WH, Vinicor F, Bales VS \& Marks JS 2003 Prevalence of obesity, diabetes, and obesity-related health risk factors, 2001. Journal of the American Medical Association 289 76-79. (doi:10.1001/jama.289.1.76)

Movahed A, Nabipour I, Lieben Louis X, Thandapilly SJ, Yu L, Kalantarhormozi M, Rekabpour SJ \& Netticadan T 2013 Antihyperglycemic effects of short term resveratrol supplementation in type 2 diabetic patients. Evidence-Based Complementary and Alternative Medicine 2013 851267. (doi:10.1155/2013/851267)

Nawrocki AR, Rodriguez CG, Toolan DM, Price O, Henry M, Forrest G, Szeto D, Keohane CA, Pan Y, Smith KM et al. 2014 Genetic deletion and pharmacological inhibition of phosphodiesterase 10A protects mice from diet-induced obesity and insulin resistance. Diabetes 63 300-311. (doi:10.2337/db13-0247)

Pari L \& Murugan P 2005 Effect of tetrahydrocurcumin on blood glucose, plasma insulin and hepatic key enzymes in streptozotocin induced diabetic rats. Journal of Basic and Clinical Physiology and Pharmacology 16 257-274. (doi:10.1515/JBCPP.2005.16.4.257)

Park SJ, Ahmad F, Philp A, Baar K, Williams T, Luo H, Ke H, Rehmann H, Taussig R, Brown AL et al. 2012 Resveratrol ameliorates aging-related metabolic phenotypes by inhibiting cAMP phosphodiesterases. Cell 148 421-433. (doi:10.1016/j.cell.2012.01.017)

Poulsen MM, Vestergaard PF, Clasen BF, Radko Y, Christensen LP, Stødkilde-Jørgensen H, Møller N, Jessen N, Pedersen SB \& Jørgensen JO
2013 High-dose resveratrol supplementation in obese men: an investigator-initiated, randomized, placebo-controlled clinical trial of substrate metabolism, insulin sensitivity, and body composition. Diabetes 62 1186-1195. (doi:10.2337/db12-0975)

Rotella DP 2002 Phosphodiesterase 5 inhibitors: current status and potential applications. Nature Reviews. Drug Discovery 1 674-682. (doi:10.1038/nrd893)

Samson SL \& Garber AJ 2014 Metabolic syndrome. Endocrinology and Metabolism Clinics of North America 43 1-23. (doi:10.1016/j.ecl.2013.09.009)

Shao W, Yu Z, Chiang Y, Yang Y, Chai T, Foltz W, Lu H, Fantus IG \& Jin T 2012 Curcumin prevents high fat diet induced insulin resistance and obesity via attenuating lipogenesis in liver and inflammatory pathway in adipocytes. PLOS ONE 7 e28784. (doi:10.1371/journal.pone.0028784)

Shoba G, Joy D, Joseph T, Majeed M, Rajendran R \& Srinivas PS 1998 Influence of piperine on the pharmacokinetics of curcumin in animals and human volunteers. Planta Medica 64 353-356. (doi:10.1055/ s-2006-957450)

Soderling SH \& Beavo JA 2000 Regulation of cAMP and cGMP signaling: new phosphodiesterases and new functions. Current Opinion in Cell Biology 12 174-179. (doi:10.1016/S0955-0674(99)00073-3)

Soldevila G, Buscema M, Marini V, Mirakian R, Deuss V, Sutton R, James R, Lake S, Robertson P, Pujol-Borrell R et al. 1991 Transfection with SV40 genes of human pancreatic endocrine cells. Journal of Autoimmunity 4 381-396. (doi:10.1016/0896-8411(91)90154-5)

Soufi FG, Sheervalilou R, Vardiani M, Khalili M \& Alipour MR 2012 Chronic resveratrol administration has beneficial effects in experimental model of type 2 diabetic rats. Endocrine Regulations 46 83-90. (doi:10.4149/ endo_2012_02_83)

Su HC, Hung LM \& Chen JK 2006 Resveratrol, a red wine antioxidant, possesses an insulin-like effect in streptozotocin-induced diabetic rats. American Journal of Physiology. Endocrinology and Metabolism 290 1339-1346. (doi:10.1152/ajpendo.00487.2005)

Szkudelski T \& Szkudelska K 2011 Anti-diabetic effects of resveratrol. Annals of the New York Academy of Sciences 1215 34-39. (doi:10.1111/j. 1749-6632.2010.05844.x)

Trimmers S, Hesselink MK \& Schrauwen P 2013 Therapeutic potential of resveratrol in obesity and type 2 diabetes: new avenues for health benefits? Annals of the New York Academy of Sciences 1290 83-89. (doi:10.1111/nyas.12185)

Waddleton D, Wu W, Feng Y, Thompson C, Wu M, Zhou YP, Howard A, Thornberry N, Li J \& Mancini JA 2008 Phosphodiesterase 3 and 4 comprise the major cAMP metabolizing enzymes responsible for insulin secretion in INS-1 (832/13) cells and rat islets. Biochemical Pharmacology 76 884-893. (doi:10.1016/j.bcp.2008.07.025)

Walz HA, Härndahl L, Wierup N, Zmuda-Trzebiatowska E, Svennelid F, Manganiello VC, Ploug T, Sundler F, Degerman E, Ahrén B et al. 2006 Early and rapid development of insulin resistance, islet dysfunction and glucose intolerance after high-fat feeding in mice overexpressing phosphodiesterases 3B. Journal of Endocrinology 189 629-641. (doi:10.1677/joe.1.06522)

Walz HA, Wierup N, Vikman J, Manganiello VC, Degerman E, Eliasson L \& Holst LS $2007 \beta$-Cell PDE3B regulates $\mathrm{Ca}^{2+}$-stimulated exocytosis of insulin. Cellular Signalling 19 1505-1513. (doi:10.1016/j.cellsig.2007.01.030)

Yoshino J, Conte C, Fontana L, Mittendorfer B, Imai S, Schechtman KB, Gu C, Kunz I, Rossi Fanelli F, Patterson BW et al. 2012 Resveratrol supplementation does not improve metabolic function in nonobese women with normal glucose tolerance. Cell Metabolism 16 658-664. (doi:10.1016/j.cmet.2012.09.015)

Younès A, Lukyanenko YO, Lyashkov AE, Lakatta EG \& Sollott SJ 2011 A bioluminescence method for direct measurement of phosphodiesterase activity. Analytical Biochemistry 417 36-40. (doi:10.1016/ j.ab.2011.05.036)

Received in final form 22 July 2014 Accepted 6 August 2014

Published by Bioscientifica Ltd 